Article

\title{
Type of physical activity, diet, BMI and tobacco/alcohol consumption relationship: How they are associated with our health?
}

\author{
Liudmila Liutsko ${ }^{1-3^{*}}$, Alexander Veraksa ${ }^{2}$, Irina Polikanova ${ }^{2,4^{*}}$ and Sergey Leonov ${ }^{2}$ \\ 1 Radiation Department, ISGlobal, 08003 Barcelona, Spain; \\ 2 Faculty of Psychology, Lomonosov Moscow State University, Moscow 125009, Russia; \\ svleonov@gmail.com (S.L.); veraksa@yandex.ru (A.V.) \\ 3 UrFU, Yekaterinburg 620075, Russia; \\ ${ }^{4}$ Faculty of Biology and Biotechnology, HSE University, Moscow 101000, Russia \\ * Correspondence: liudmila liutsko@yahoo.es (L.L.)
}

\begin{abstract}
The purpose of this article was to check the effects on health of various types of physical activities, diet, BMI, smoking and alcohol consumption and their interrelationships with control for age, sex and level of education. The study was based on epidemiological data (9617 participants from 19 to 81 years old for whom we have health indicators over a period of 11 years) together with questionnaires about diet, alcohol, tobacco and the frequency of different types of physical activities. Descriptive statistics and non-parametric correlational analysis of epidemiological data was performed with use of SPSS v.19. Our results indicate the existence of the significant relationship between leading a healthy life style (type of physical activities, limitations of fats consume and weight maintenance). However, the different categories of physical activities were analysed separately and showed slight differences on health indicators impacts. Our findings confirm that leading a healthy life style (all types of physical activities, limitations of fats consume and weight maintenance) is an important issue since it has a significant relationship with physical and mental health indicators, but outdoor physical activities and practicing sport in group have shown slightly higher impact on health.
\end{abstract}

Keywords: healthy life style; physical activit; physical and mental health

\section{Introduction}

Physical activity is a rather vague term, which includes a wide variety of types of differing intensity and frequency. In the most general way it is defined as an increase of energy expenditure by moving one's body [1,2]. Some researchers mention the importance of covering different domains of physical activity instead of referring only to sport and exercise. Those are walking, cycling, leisure time, housework, transportation, and occupational components of physical activity [3-5]. Exercising in nature is viewed as more effective than in the urban setting [6].

There is no consensus on what frequency, duration, and intensity of physical activity is defined as "healthy" $[7,8]$. In several papers it is advised for general public to exercise moderately five days per week for about half an hour each time $[6,8,9]$ and somewhat more for patients with depression [10]. Physical activity is measured either through self-reports [4] or using pedometers, which appeared to be a valid means correlating with self-reports [11]. In different papers physical activity is classified into different levels, most often high, moderate and low [3, 4]. In the position statement on physical activity and exercise intensity terminology Norton, Norton, and Sadgrove offer a more distinct designation of physical activity: sedentary, light, moderate, vigorous or high [12]. However, for the purpose of our research we have decided to focus on the moderate level of physical activity. It is shown that significant physiological change may happen with small increases in exercise intensity, these processes are similar in all healthy adults [12], and that the greatest effectiveness may be reached in the medium tertile physical activity [4]. 
There is an increased focus on physical activity as a possible solution in public health regarding its numerous positive effects. A number of research findings shows that an individual may benefit from being physically active in terms of general physical and mental health, emotional, psychological and general well-being.

Sport and exercise have positive effects on overall physical health [4, 13-17] and reduce all-cause mortality [18]. Particularly regular physical activity is said to be cardio protective [5, 8], reducing the cardiovascular and cerebrovascular risk [4, 19] and the risk of stroke [11, 19]. It supports treatment and prevention of non-alcoholic fatty liver disease [19] and of obesity [9, 20]. Moreover, it helps manage several chronic conditions such as diabetes, heart disease [9] and slows down the progression of atherosclerosis [4].

Mental health is another dimension of the human condition that has showed to have positive outcomes for people who are physically active [22]. Regular exercise lowers anxiety, alleviates posttraumatic stress disorder (PTSD), social phobia (SP) and obsessive-compulsive disorder (OCD) [1]. It is effective as an adjuvant treatment in major depressive disorder [8], helps improve functioning parameters in depressed patients, lowers depression symptoms [8, 10]. It also helps maintain cognitive function [5, 23, 24].

Adequate levels of physical activity have shown to result in emotional well-being. Not only does exercise deliver pleasurable feelings and energy [6], but also those who practice it rarely develop mood disorders [1]; some authors mention a decrease in negative or an increase in positive affect [20]. Psychological benefits, apart from emotional well-being, are reducing stress, better sleep [6, 14], improving self-esteem and better functioning in social, working and leisure contexts [1, 14]. Being physically active is related to overall subjective well-being [8, 14, 25] and quality of life [20] including higher long-term income [13], slower or partially reversed ageing process [5] and a greater chance to live longer independently in older ages [9].

Among negative effects of physical activity are mentioned its anxiogenic effect [1] and an increased risk of heart attack [4], both being related to a high or vigorous levels of activity. There may be more serious negative outcomes when the level of exercise is higher than an individual's physical capacity, which appears to be a risk for many people. Namely being highly physically active is over the maximal capacity of one-third of young adults (18-29 years old) and almost half of the people in the middle of adulthood (30-39 years old) [12].

However, there is an ambiguity of findings in different research concerning effects of physical exercise $[4,10,20]$. Some researchers believe it is due to a lack of good studies in the field [1,8]. In this study we address methodological difficulties mentioned by those scholars in the following ways. First of all, it is a larger sample size. Secondly, it is a narrower focus on the moderate intensity and a clear definition of different types of physical activity.

Lifestyle is another important term for this research because physical activity and other lifestyle factors are interdependent in many ways $[3,5]$. According to a number of scholars, lifestyle factors or elements of healthy lifestyle are: regular moderate physical activity [7, 26, 27], avoiding smoking [14, 28, 29], moderate alcohol consumption [7, 26], maintaining normal weight [27-29], diet [7] mostly meaning consuming more fruits, vegetables, fish, and milk [27-29]. Eguchi et al. [27] add to this list moderate sleep duration, and Södergren et al. [5] add TV viewing. Lifestyle can also be seen, as Macovei, Tufan, and Vulpe [14] put it, as physical exercise plus avoiding any kind of abuse.

Wholesome lifestyle is viewed as paramount for maintaining one's health status [14] including longer life duration, postponement of age associated diseases [5], better mental health [1] normal body weight [24], and lower risk of mortality [7]. Lifestyle behaviors are more beneficial together: researchers show that combined synergistic effect of positive lifestyle factors result in better health status, including weight and lower mortality risk $[5,7,26]$.

As opposed to an active way of living there is a notion of "sedentary behavior"; some of the scientists emphasize that it is not the same as physical inactivity, though they are related [5]. It is shown to be linked to obesity [9], mortality [6] and depression [20]. Negative lifestyle choices include also smoking, excessive alcohol consumption, unhealthy diet, etc. and are associated with higher 
mortality risk [5, 28] and a range of health problems, such as cardiovascular disease [28], obesity [30], incidence of stroke [27], and major non-communicable disease [7].

Smoking alone is related to a range of health problems, including mood and anxiety disorders [1], earlier aging and death [5]. Along with physical activity it is seen as one of the most important lifestyle factors in terms of preventing chronic diseases [5, 7]. Interdependence of smoking and physical activity is controversial. Negative effects of smoking are more detrimental for physically inactive youth, as Katano, Ohno, and Yamada show, and high intensity exercise may be protective in terms of maximum carotid intimamedia thickness (IMT) [4]. Henchoz et al. citing other authors mention that sportive activity was show to have a negative correlation with smoking and positive with alcohol use. They have discovered a similar result: all sorts of physical activity were associated with at-risk use of alcohol, and all sorts of it apart from sport and exercise are associated with at-risk use of cigarettes and cannabis [3].

Unhealthy lifestyle patterns are prevalent nowadays and the number of people who cling to them is growing in the whole world [14, 28, 30,31]. Its negative effects put pressure on social and health care sectors [5, 7, 9]. Unhealthy lifestyle can be self-reinforcing [9]. One research has shown that there is a lack of belief in one's ability to live a healthy lifestyle, and it is negatively related to reported healthier behaviors in children [32]. Other paper displayed that many adult individuals lack the ability required to change their lifestyle [18].

Lifestyle modification is beneficial in different ages and health status [27, 29], but Fenner et al. claim that there is a lack of interventions that promote such a modification [33]. However, some lifestyle intervention programs have shown to be effective against adiposity [35], stroke risk factors [11, 27], recession of cognitive function and brain metabolism [21], and excessive use of Primary Health Care center, meaning that patients who went through an intervention program would visit health center less frequently [25]. New technologies are at work: the application STEP UP helps increase the motivation to walk more, and adding a social component was found to be important [9]. The program "Healthy Dads, Healthy Kids" working with overweight fathers and their children was effective in increasing the number of healthy behaviors and decreasing weight in fathers and children [30]. The World Health Organization encourages to promote physical activity to be healthier with its program "Global action plan on physical activity 2018-2030: more active people for a healthier world" [35].

This study's main strengths were having a large representative sample from the general population and simple categories defining physical activity, making it easier to identify for general public. Our findings add experimental evidence in support of extant research [25] to suggest a positive influence of physical activity on reducing the frequency of visits to a doctor. This data is needed to better tailor further interventions. It is important to know more about the association between healthy lifestyle behaviors and physical activity in order to better formulate public health strategies. The novelty of this study is to see different types of physical effects on health indicators and interrelationships with diet, maintaining of weight, BMI, tobacco and alcohol consumption. The preliminary results of this study have been presented at the ISEE (International Society of the Environmental Epidemiology) conference [36].

\section{Materials and Methods}

This is a secondary analysis of data study. In original study was based at general Belgium population with involvement of 9617 participants from 19 to 81 years old ( $M=56.5, S D=13.3,56 \%$ female). The demographic data (age, level of studies, BMI) and epidemiological data such as days of hospitalization in general and psychiatric clinics, number of the corresponded doctor's visits, daily medical drug and alternative medicine (vitamins, antiinflammatory drugs, etc.) consumption were collected together with questionnaire about doing three types of physical exercises (1 - sport activities as aerobics, running, biking, swimming, Nordic walking; 2 - exercises of yoga type - yoga, Tai-Chi, stretching, Pilates, and 3 - physical activities like gardening, practicing sport in group - golf, football, ) and leading of a healthy life style (a healthy diet: like avoiding fats and keeping variability in daily menu, keeping a normal weight, also observing such parameters of bad habits as smoking 
and alcohol consumption) (see Appendix for more details). The descriptive and correlational analysis were performed with use of SPSS v.19.

The original study received approval from the Ethical Committee of the Psychological Science Department and from the collaborative entity Mutualité Chrétienne-Christelijke Mutualiteit (MC$\mathrm{CM})$, the law service of the Mutual Benefity Society and their financial and organization help. All respondents received detailed information about the study and the data processing and provided separate written consent for the questionnaire study and the coupling of their answers with their medical records in possession of the MC-CM. Only people who provided written consent for both parts were included in the study. The realization of this study (planning of the hypothesis and data analysis) was supported by the MC-CM, by the 2012 Belgian-American Education Foundation (BAEF) alumni awarded granted to M.M. The MC-CM helped for the data collection by providing us with the email address of their members and by providing us with the health records of people who consent that we coupled their answers with their health records. None of our funding providers had any role in the data analyses and interpretation, or had any right to approve or disapprove the writing and publication of the manuscript.

\section{Results}

The observable variables, taken from the epidemiological data for an adult Belgian population, can be described by two general categories: 1) healthy life style (consisted in keeping weight and less consumption of fatty food products, a variable diet; as well as by practicing sport or other physical activities) and 2) health indicators (medical and alternative drugs consumption, number of days spent in general and psychiatric hospitals, number of visit or doctors' consultations). Other factors of bad habits (smoking alcohol consumption), age and education were shown also (Table 1).

Table 1. Descriptive statistics for observable variables

\begin{tabular}{lcccc}
\hline & M & SD & Min & Max \\
\hline BMI & 26.18 & 4.76 & 19.25 & 73.25 \\
Diet (variability in menu) & 2.72 & 0.53 & 1 & 3 \\
Diet (avoidance of consuming of fats) & 2.46 & 0.64 & 1 & 3 \\
Keeping the normal weight & 2.38 & 0.72 & 1 & 3 \\
$\begin{array}{l}\text { 1) Sport (aerobics, running and swimming } \\
\text { type) }\end{array}$ & 1.87 & 0.83 & 1 & 3 \\
2) Exercises of yoga type & 1.18 & 0.49 & 1 & 3 \\
$\begin{array}{l}\text { 3) Other physical and group sport } \\
\text { activities }\end{array}$ & 1.90 & 0.79 & 1 & 3 \\
$\begin{array}{l}\text { Smoking } \\
\text { Alcohol consumption }\end{array}$ & 1.25 & 0.64 & 1 & 3 \\
$\begin{array}{l}\text { Drug consumption in Daily Defined Dose } \\
\text { (sum 2001-2012) }\end{array}$ & 1.50 & 0.71 & 1 & 3 \\
$\begin{array}{l}\text { Number of days spent at the hospital } \\
\text { (general hospital) 2001-2011-exc2007 }\end{array}$ & 6003 & 7153 & 0 & 73378 \\
$\begin{array}{l}\text { Number of days spent at the hospital } \\
\text { (psychiatric hospital) 2001-2011-exc2007 }\end{array}$ & 10 & 34 & 0 & 897 \\
$\begin{array}{l}\text { Number of doctor consultations (GP and } \\
\text { SP 2001-2011) }\end{array}$ & 95 & 71 & 0 & 1353 \\
$\begin{array}{l}\text { Number of visits to a psychiatrist (SUM } \\
\text { 2001-2012) }\end{array}$ & 4 & 25 & 0 & 986 \\
Alternative (non-reimbursed) medicine & 2 & 1 & 1 & 5 \\
\hline
\end{tabular}


The correlational analysis was performed in order to see the significant relationship between the observed variables of the healthy life style and health indicators, checking also other variables of possible important effects, such as age and level of study (Table 2).

Table 2. Correlational analysis of the observed parameters (Spearman's rho)

\begin{tabular}{|c|c|c|c|c|c|c|}
\hline & $\begin{array}{l}\text { Number of day } \\
\text { spent at the } \\
\text { hospital } \\
\text { (general) }\end{array}$ & 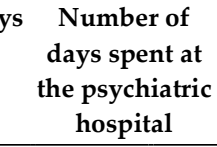 & $\begin{array}{c}\text { Number of } \\
\text { doctor } \\
\text { consultatio } \\
\text { ns (GP) }\end{array}$ & $\begin{array}{l}\text { Number of } \\
\text { visits to a } \\
\text { psychiatrist }\end{array}$ & $\begin{array}{c}\text { Drug } \\
\text { consumption in } \\
\text { Daily Defined } \\
\text { Dose } \\
\end{array}$ & $\begin{array}{l}\text { Non- } \\
\text { reimbursed } \\
\text { medicine }\end{array}$ \\
\hline $\begin{array}{l}\text { 1) Sport activities of } \\
\text { aerobic type }\end{array}$ & $-.119^{* * *}$ & $-.033^{* *}$ & $-.108^{* * *}$ & $-.048^{* * *}$ & -.014 & $-.042^{* * *}$ \\
\hline $\begin{array}{l}\text { 2) Exercises of yoga } \\
\text { type }\end{array}$ & $-.029^{* *}$ & -.003 & -.003 & $-.030^{* *}$ & $.068^{* * *}$ & $.141^{* * *}$ \\
\hline $\begin{array}{l}\text { 3) Other physical } \\
\text { activities (gardening, } \\
\text { group sport) }\end{array}$ & $-.137^{* * *}$ & $-.057^{* * *}$ & $-.126^{* * *}$ & $-.081^{* * *}$ & $-.141^{* * *}$ & $-.074^{* * *}$ \\
\hline $\begin{array}{l}\text { Limitation of fats } \\
\text { consume }\end{array}$ & -.016 & $-.049^{* * *}$ & $.093^{* * *}$ & -.017 & $.057^{* * *}$ & $.079^{* * *}$ \\
\hline Maintenance of weight & $-.056^{* * *}$ & $-.052^{* * *}$ & $-.038^{* * *}$ & $-.049^{* * *}$ & $-.100^{* * *}$ & -.001 \\
\hline $\mathrm{BMI}$ & $.101^{* * *}$ & .011 & $.132^{* * *}$ & -.012 & $.268^{* * *}$ & $-.026^{* *}$ \\
\hline Variability in menu & $-.068^{* * *}$ & $-.090^{* * *}$ & $-.028^{* *}$ & $-.103^{* * *}$ & $-.046^{* * *}$ & -.009 \\
\hline Smoking & $.059^{* * *}$ & $.138^{* * *}$ & .010 & $.102^{* * *}$ & $.022^{*}$ & $.037^{* * *}$ \\
\hline Alcohol consume & $-.053^{* * *}$ & -.014 & $-.060^{* * *}$ & $-.048^{* * *}$ & .008 & $-.063^{* * *}$ \\
\hline Level of studies & $-.111^{* * *}$ & $-.026^{* *}$ & $-.186^{* * *}$ & $.065^{* * *}$ & $-.173^{* * *}$ & $-.059^{* * *}$ \\
\hline Age & $.105^{* * *}$ & $-.087^{* * *}$ & $.244^{* * *}$ & $-.153^{* * *}$ & $.349^{* * *}$ & $-.020^{*}$ \\
\hline
\end{tabular}

Legend: level of significance: ${ }^{*}-\mathrm{p}<.05 ;{ }^{* *}-\mathrm{p}<.01$, and ${ }^{* * *}-\mathrm{p}<.001$.

The results showed that all sport and/or physical activities had significant relationship with a negative sign with number of days spent in general hospital and number of visit of psychiatrist. Sport type 1 (aerobics, running, swimming, etc.) and type 3 (group sport exercises and other physical activities as gardening), but not type 2 (exercises of yoga type) had a significant negative relationship with a number of days spent in psychiatric hospital and visits of general doctors (GP general physician) (Table 2). Moreover, the first and the third category of the sport or/and physical activities had a significant correlation of positive sign between them (rho=.52, $\mathrm{p}<.001$ ). As far as for medical and alternative (vitamins, etc.) drug consumption concern, yoga type exercises had a positive significant correlation, whereas other sport or physical activities had a negative one. The sport type 1 had reached a statistically significant level only with non-reimbursed medicine.

Keeping weight at the normal level had a negative significant relationship with all observable health indicator variables except on the non-reimbursed drug consumption; however, the avoidance of fats consumption had a negative significant relationship with the number of days spent in psychiatric hospital only, and a positive one with the number of general doctor's consultations and drug consumption of both types. The BMI (body mass index) had a significant correlation of positive sign with a duration period in general hospital, number of visiting of general doctors and medical drug consumption (Table 2). 
Variability in menu and keeping a healthy and balance diet had a negative relationship with all health indicators, statistically significant except of the consumption of non-reimbursed drugs. Smoking showed a positive relationship, whereas the alcohol consumption, a negative one, with the majority of health indicators (Table 2). In addition, the alcohol consumption was positively correlated at statistically significant level with the all activities except on yoga type; whereas smoking was correlated negatively with all type of physical activities. Smoking had a positive significant correlation on alcohol consumption $(\mathrm{rho}=.067, \mathrm{p}<.01)$. All types of physical activities were positively and significantly related with keeping the weight at norm (Table 3 ).

Table 3. Sport activities and healthy habits

\begin{tabular}{|c|c|c|c|}
\hline Activities & $\begin{array}{c}\text { Weight } \\
\text { maintenance }\end{array}$ & Smoking & $\begin{array}{c}\text { Alcohol } \\
\text { consumption }\end{array}$ \\
\hline 1. Sport (aerobics, running, swimming, etc.) & $.268^{* * *}$ & $-.150^{* * *}$ & $.040^{* * *}$ \\
\hline 2. Exercises of yoga type & $.116^{* * *}$ & $-.050^{* *}$ & .000 \\
\hline $\begin{array}{l}\text { 3. Physical activities (gardening) and/or sport in } \\
\text { group (golf, volleyball, etc.) }\end{array}$ & $.285^{* * *}$ & $-.111^{* * *}$ & $.060^{* * *}$ \\
\hline
\end{tabular}

Legend: level of significance: ${ }^{*}-\mathrm{p}<.05 ;{ }^{* *}-\mathrm{p}<.01$, and ${ }^{* *}-\mathrm{p}<.001$.

From the other observed variables, age had negative significant correlations with numbers of days spent in general hospital, number of visit with general doctors and medical drug consumption, whereas it had a negative relationship with number spent in psychiatric hospitals, visits of psychiatrists and consumption of non-reimbursed drugs. The level of studies was also checked to have the significant relationship with all health indicator observable variables of negative sign, except on number of visits with psychiatrist, where it was of the positive sign (Table 2).

\section{Discussion}

The study carried out in such large sample allows making general conclusions about the relationships of the indicators of leading a healthy life style and general indicators of physical and mental health. Having all them together, the comparative analysis of the magnitude of the effects enables to observe the most influent parameters. Thus, for the observable variable of number of days spent in general hospital, the most important protective factors were physical exercises type 3 (gardening and sport in groups), sport type 1 (aerobics, running, walking, etc.) and level of study (all of them with a negative sign, or reductive effect), followed by the age and BMI (with a positive sign, or increasing effect). As for the numbers of days in total spent in psychiatric hospital, the highest effect was related to smoking (a positive relationship, a risk factor), followed by age, use of variability and balance diet (menu) and physical exercises type 3 (last three with a negative correlation, protective factors). Number of general doctor's visits was more highly related to the age (positively), level of study (negatively), BMI (positively) and practicing of physical activities type 3 (negatively); whereas number of visits of psychiatrists was more related to age (negatively), use of variable menu (negatively), smoking (positively) and physical activities type 3 (negatively). Medical drug consumption was more related to age and BMI (both with a positive sign), followed by level of study and physical exercises type 3 (both with a negative sign); whereas the non-reimbursed drugs consumption had the most important factors such as sex (in favour of women), followed by limitation of fat consumption (a positive relationship) and physical exercises type 3 (gardening, golf, volleyball, etc.).

One of the limitations of study consist on difficulty of direct effects or causality by the existing relationship since this study reports the associations that sometimes also difficult to interpret. For example, alcohol consumption was negatively related to number of days spent at the general hospital and doctor's visits of both category (general and psychiatrist); however, it could not be interpreted directly: "to consume more alcohol would benefit your health" since there could be other indirect 
causes of such reduction, more specific to these problem and related behaviour. Anyway our results were congruent to some extent to the Henchoz's ones [3] since all sport and physical exercises except of type 2 (yoga type) were positively correlated with alcohol consumption (and all of them were negatively related to smoking). A positive relation of alcohol consumption for those who practice sport sometimes is interpreted as factor of "socialization" with others.

\section{Conclusions}

To sum up the obtained results indicate the existence of the significant relationship between leading a healthy life style (all three observed types of physical activity, variable and less in fats diet and nonsmoking). However, group sport and physical activities as gardening seemed to have higher impact (as per correlational coefficient) on the observed health indicators, followed by sport exercises of aerobics, running and swimming type and. Yoga type exercises also had protective role for such health indicators as numbers of days spent in general hospital and umbers of visits to psychiatrist; but it had positive associations with medical drug consumption.

\section{Practical Implications.}

Leading a healthy life style (practicing sport or doing other physical activities, variable and low fats content diet with non-smoking) is a protective mechanism for our physical and mental health.

Practising the physical and sport activities, maintain weigh in normal parameters (BMI) and variability in a diet (menu) were the most important components confirmed by this study for our health together with effects of level of study (excluding the positive relationship with number of visits of psychiatrists), age and habits in smoking.

Physical exercises can be related to less risk of tobacco consumption and higher risk (but to a less magnitude comparing to smoking) of alcohol consumption (all exercises type except of yoga type). From three types of physical activities (1 - aerobic, running, swimming, etc. type; 2 - yoga type, and 3 - group sport or other physical activities as gardening), the last one and first one had more impact on the observed health variables as hospitalization duration, number of doctors' visits and medical or alternative drug consumption.

Author Contributions: Conceptualization, S.L., L.L., A.V.; methodology, S.L. and L.L.; software, I.P. and S.L.; validation, I.P. and L.L.; formal analysis, L.L., A.V.; investigation, A.V., I.P. and L.L.; resources, S.L. and A.V.; data curation, A.V., I.P. and L.L.; writing - original draft preparation, I.P. and L.L.; writing - review and editing, S.L. and L.L.; visualization, I.P.; supervision, S.L. and L.L.; project administration, L.L.; funding acquisition, S.L. and L.L. All authors have read and agreed to the published version of the manuscript.

Funding: This research was funded by the Russian Foundation for Basic Research, grant number 19-013-00951.

Institutional Review Board Statement: Not applicable since it is a secondary analysis of data (and anonymized data bases). The original study received approval from the Ethical Committee of the Psychological Science Department and from the collaborative entity Mutualité Chrétienne-Christelijke Mutualiteit (MC-CM), the law service of the Mutual Benefity Society and their financial and organization help.

Informed Consent Statement: Not applicable (secondary data analysis). In the original study all respondents received detailed information about the study and the data processing and provided separate written consent for the questionnaire study and the coupling of their answers with their medical records in possession of the MC-CM. Only people who provided written consent for both parts were included in the study.

Acknowledgments: We are grateful to Dr. Moira Mikolajczak for her critical comments and also support with data for this study, as well as to University of Louvain and the law department of the Mutualité ChrétienneChristelijke Mutualiteit.

Conflicts of Interest: The authors declare no conflict of interest. 
8 of 10

Appendix 1: Questionnaire

Sport \& Physical exercices:

1) (sport) I practice a physical activity (i.e., running, swimming, aerobics, Nordic walking ...) for 15 to 30 minutes at least 3 times per week ( 1 - almost never, 2 - sometimes, 3 - almost always)

2) (exercises of yoga type) I practice yoga, stretching, Tai-Chi, Pilates or the like for 15 to 30 minutes at least 3 times per week ( 1 - almost never, 2 - sometimes, 3 - almost always)

3) (other physical \& sport activities): I use some of my free time to participate in activities that maintain my condition (gardening, golf, football, sports group) (1 - almost never, 2 - sometimes, 3 - almost always)

\section{Healthy life style (others):}

4) (maintenance of the weight) : I keep appropriate weight myself avoiding overweight and underweight (1 almost never, 2 - sometimes, 3 - almost always)

5) (avoidance of fats consumption) : I limit the amount of fat, saturated fat and cholesterol in my diet (including the fat in the meat, eggs, butter, sour cream or meat ) (1 - almost never, 2 - sometimes, 3 - almost always)

6) (variability in a daily menu) I eat a varied menu each day, and I consumed such as fruits and vegetables, bread and whole grains, lean meats, dairy products, nuts and seeds (1 - almost never, 2 - sometimes, 3 - almost always)

7) (smoking) I smoke more than two cigarettes a day (1 - almost never, 2 - sometimes, 3 - almost always)

8) (alcohol consumption) I drink at least 2 glasses of alcoholic beverages per day (1 - almost never, 2 - sometimes, 3 - almost always) 
9 of 10

\section{References}

1. Moylan, S., Eyre, H. A., Maes, M., Baune, B. T., Jacka, F. N., \& Berk, M. (2013). Exercising the worry away: how inflammation, oxidative and nitrogen stress mediates the beneficial effect of physical activity on anxiety disorder symptoms and behaviours. Neuroscience \& Biobehavioral Reviews, 37(4), 573-584.

2. Westerterp, K. R. (2017). Control of energy expenditure in humans. European journal of clinical nutrition, 71(3), 340-344.

3. Henchoz, Y., Dupuis, M., Deline, S., Studer, J., Baggio, S., N'Goran, A. A., ... \& Gmel, G. (2014). Associations of physical activity and sport and exercise with at-risk substance use in young men: A longitudinal study. Preventive medicine, 64, 27-31.

4. Katano, H., Ohno, M., \& Yamada, K. (2013). Protection by physical activity against deleterious effect of smoking on carotid intima-media thickness in young Japanese. Journal of Stroke and Cerebrovascular Diseases, 22(2), 176-183.

5. Södergren, M., Wang, W. C., Salmon, J., Ball, K., Crawford, D., \& McNaughton, S. A. (2014). Predicting healthy lifestyle patterns among retirement age older adults in the WELL study: a latent class analysis of sex differences. Maturitas, 77(1), 41-46.

6. Kinnafick, F. E., \& Thøgersen-Ntoumani, C. (2014). The effect of the physical environment and levels of activity on affective states. Journal of Environmental Psychology, 38, 241-251.

7. Loef, M., \& Walach, H. (2012). The combined effects of healthy lifestyle behaviors on all cause mortality: a systematic review and meta-analysis. Preventive medicine, 55(3), 163-170.

8. Mota-Pereira, J., Silverio, J., Carvalho, S., Ribeiro, J. C., Fonte, D., \& Ramos, J. (2011). Moderate exercise improves depression parameters in treatment-resistant patients with major depressive disorder. Journal of psychiatric research, 45(8), 1005-1011.

9. Khalil, A., \& Abdallah, S. (2013). Harnessing social dynamics through persuasive technology to promote healthier lifestyle. Computers in Human Behavior, 29(6), 2674-2681.

10. Stanton, R., \& Reaburn, P. (2014). Exercise and the treatment of depression: a review of the exercise program variables. Journal of Science and Medicine in Sport, 17(2), 177-182.

11. Silva-Smith, A. L., Fleury, J., \& Belyea, M. (2013). Effects of a physical activity and healthy eating intervention to reduce stroke risk factors in older adults. Preventive medicine, 57(5), 708-711.

12. Norton, K., Norton, L., \& Sadgrove, D. (2010). Position statement on physical activity and exercise intensity terminology. Journal of Science and Medicine in Sport, 13(5), 496-502.

13. Hyytinen, A., \& Lahtonen, J. (2013). The effect of physical activity on long-term income. Social Science \& Medicine, 96, 129-137.

14. Macovei, S., Tufan, A. A., \& Vulpe, B. I. (2014). Theoretical approaches to building a healthy lifestyle through the practice of physical activities. Procedia-Social and Behavioral Sciences, 117, 86-91.

15. Malm, C., Jakobsson, J., \& Isaksson, A. (2019). Physical activity and sports - real health benefits: a review with insight into the public health of Sweden. Sports, 7(5), 127.

16. Osipov, A., Kudryavtsev, M., Fedorova, P., Serzhanova, Z., Panov, E., Zakharova, L., ... \& Klimuk, Y. (2017). Components of positive impact of exposure on university physical culture and sports on students' physical activity.

17. Schwartz, J., Rhodes, R., Bredin, S. S., Oh, P., \& Warburton, D. E. (2019). Effectiveness of approaches to increase physical activity behavior to prevent chronic disease in adults: a brief commentary. Journal of clinical medicine, 8(3), 295.

18. Södergren, M. (2013). Lifestyle predictors of healthy ageing in men. Maturitas, 75(2), 113-117.

19. Centis, E., Moscatiello, S., Bugianesi, E., Bellentani, S., Fracanzani, A. L., Calugi, S., ... \& Marchesini, G. (2013). Stage of change and motivation to healthier lifestyle in non-alcoholic fatty liver disease. Journal of hepatology, 58(4), 771-777.

20. Centis, E., Petroni, M. L., Ghirelli, V., Cioni, M., Navacchia, P., Guberti, E., \& Marchesini, G. (2020). Motivational Interviewing Adapted to Group Setting for the Treatment of Relapse in the Behavioral Therapy of Obesity. A Clinical Audit. Nutrients, 12(12), 3881.

21. Suminski, A. (2020). Physical Activity Interventions for Older Adults: Efficacy, Adherence and Sustainability for Stroke Prevention Outcomes. DePaul Discoveries, 9(1), 8.

22. Sun, Y. C., Chao, C. L., \& Huang, M. N. (2014). Psychological effects of physical activity: A quasi-experiment in an indigenous community. Tzu Chi Medical Journal, 26(1), 29-33. 
23. Small, G. W., Silverman, D. H., Siddarth, P., Ercoli, L. M., Miller, K. J., Lavretsky, H., ... \& Phelps, M. E. (2006). Effects of a 14-day healthy longevity lifestyle program on cognition and brain function. The American journal of geriatric psychiatry, 14(6), 538-545.

24. Mann, J., Gray, T., Truong, S., Sahlberg, P., Bentsen, P., Passy, R., ... \& Cowper, R. (2021). A systematic review protocol to identify the key benefits and efficacy of nature-based learning in outdoor educational settings. International Journal of Environmental Research and Public Health, 18(3), 1199.

25. Giné-Garriga, M., Martin-Borràs, C., Puig-Ribera, A., Martín-Cantera, C., Solà, M., Cuesta-Vargas, A., \& PPAF Group. (2013). The effect of a physical activity program on the total number of primary care visits in inactive patients: A 15-month randomized controlled trial. PLoS One, 8(6), e66392.

26. Bulló, M., Garcia-Aloy, M., Martínez-González, M. A., Corella, D., Fernández-Ballart, J. D., Fiol, M., ... \& Salas-Salvadó, J. (2011). Association between a healthy lifestyle and general obesity and abdominal obesity in an elderly population at high cardiovascular risk. Preventive medicine, 53(3), 155-161.

27. Eguchi, E., Iso, H., Tanabe, N., Yatsuya, H., Tamakoshi, A., \& Japan Collaborative Cohort Study Group. (2014). Is the association between healthy lifestyle behaviors and cardiovascular mortality modified by overweight status? The Japan Collaborative Cohort Study. Preventive medicine, 62, 142-147.

28. King, D. E., Mainous III, A. G., Carnemolla, M., \& Everett, C. J. (2009). Adherence to healthy lifestyle habits in US adults, 1988-2006. The American journal of medicine, 122(6), 528-534.

29. King, D. E., Mainous III, A. G., \& Geesey, M. E. (2007). Turning back the clock: adopting a healthy lifestyle in middle age. The American journal of medicine, 120(7), 598-603.

30. Morgan, P. J., Collins, C. E., Plotnikoff, R. C., Callister, R., Burrows, T., Fletcher, R., ... \& Lubans, D. R. (2014). The 'Healthy Dads, Healthy Kids' community randomized controlled trial: A community-based healthy lifestyle program for fathers and their children. Preventive Medicine, 61, 90-99.

31. Leh, O. L. H., Shaharom, N. H., Marzukhi, M. A., \& Abdullah, J. (2020). Healthy Lifestyles and Noncommunicable Diseases (NCD) among Urban Residents. Case Study: Sri Pahang Public Housing, Bangsar, Kuala Lumpur. Environment-Behaviour Proceedings Journal, 5(SI3), 255-260.

32. O'Haver, J., Jacobson, D., Kelly, S., \& Melnyk, B. M. (2014). Relationships among factors related to body mass index, healthy lifestyle beliefs and behaviors, and mental health indicators for youth in a title 1 school. Journal of Pediatric Health Care, 28(3), 234-240.

33. Fenner, A. A., Straker, L. M., Davis, M. C., \& Hagger, M. S. (2013). Theoretical underpinnings of a needsupportive intervention to address sustained healthy lifestyle changes in overweight and obese adolescents. Psychology of Sport and Exercise, 14(6), 819-829.

34. Borel, A. L., Nazare, J. A., Smith, J., Alméras, N., Tremblay, A., Bergeron, J., ... \& Després, J. P. (2012). Improvement in insulin sensitivity following a 1-year lifestyle intervention program in viscerally obese men: contribution of abdominal adiposity. Metabolism, 61(2), 262-272.

35. World Health Organization. (2019). Global action plan on physical activity 2018-2030: more active people for a healthier world. World Health Organization.

36. Liutsko, L., Mikolajczak, M., Veraksa, A., \& Leonov, S. (2018). OP VIII-4 Type of physical activity, diet, bmi and tobacco/alcohol consumption relationship: which of them affect more our health? 